Article

\title{
Free Transverse Vibration of Rectangular Orthotropic Plates with Two Opposite Edges Rotationally Restrained and Remaining Others Free
}

\author{
Yuan Zhang ${ }^{1}$ and Sigong Zhang ${ }^{2, *}$ \\ 1 College of Architecture and Transportation, Liaoning Technical University, Fuxin 123000, China; \\ zhangyuan@Intu.edu.cn \\ 2 Department of Civil and Environmental Engineering, University of Alberta, Edmonton, \\ AB T6G 2R3, Canada \\ * Correspondence: sigong@ualberta.ca
}

Received: 28 November 2018; Accepted: 18 December 2018; Published: 21 December 2018

\begin{abstract}
Many types of engineering structures can be effectively modelled as orthotropic plates with opposite free edges such as bridge decks. The other two edges, however, are usually treated as simply supported or fully clamped in current design practice, although the practical boundary conditions are intermediate between these two limiting cases. Frequent applications of orthotropic plates in structures have generated the need for a better understanding of the dynamic behaviour of orthotropic plates with non-classical boundary conditions. In the present study, the transverse vibration of rectangular orthotropic plates with two opposite edges rotationally restrained with the remaining others free was studied by applying the method of finite integral transforms. A new alternative formulation was developed for vibration analysis, which provides much easier solutions. Exact series solutions were derived, and the excellent accuracy and efficiency of the method are demonstrated through considerable numerical studies and comparisons with existing results. Some new results have been presented. In addition, the effect of different degrees of rotational restraints on the mode shapes was also demonstrated. The present analytical method is straightforward and systematic, and the derived characteristic equation for eigenvalues can be easily adapted for broad applications.
\end{abstract}

Keywords: rectangular orthotropic plate; transverse vibration; finite integral transform; rotationally restrained edges; free edges; rotational fixity factors

\section{Introduction}

In Civil Engineering, many types of bridge decks and floor systems can be effectively modeled as orthotropic plates with opposite free edges. In practice, the other two edges of these structures are mostly not classical (i.e., neither simply supported nor fully clamped). In order to consider actual boundary conditions, these edges are intermediate between simply-supported and fully-clamped, which can be modelled as elastically restrained against rotation (i.e., rotationally restrained). However, vibration analysis of plate structures with non-classical boundary conditions involves complicated mathematical procedures. Therefore, in the design practice, the analyses of bridge decks and floors are often simplified based on a beam idealization. This simplification is not always suitable for short-span plate structures. Motivated by the extensive applications of structurally orthotropic plates in engineering structures, the present investigation deals with free transverse vibration of the rectangular orthotropic plates with two opposite edges rotationally restrained and leaving the remaining others free (i.e., R-F-R-F).

A considerable amount of literature has been published on analytical solutions for vibration of orthotropic plates with classical boundary conditions such as simply supported, clamped, 
and free [1-4]. In parallel, vibration of rectangular plates with elastically restrained edges has attracted considerable attention since the 1950s [5-11]. These studies focused primarily on the approximate estimation of natural frequencies by using Rayleigh method and Ritz method. Furthermore, most studies were devoted to isotropic plates with elastically restrained and simply supported edges. Limited research has been conducted to study orthotropic plates with elastically restrained and free edges. Laura and his colleagues [12,13] investigated orthotropic plates with three edges elastically restrained and the fourth edge free (i.e., $\mathrm{R}-\mathrm{R}-\mathrm{R}-\mathrm{F}$ ) and two adjacent edges elastically restrained and the other adjacent edges free (i.e., R-R-F-F) by Rayleigh method. Similarly, orthotropic plates with the edges elastically restrained against rotation and a free, straight corner cut-out was studied in [14]. The results reported in these three works are limited to the fundamental frequency. Grace and Kennedy [15] studied the dynamic response of orthotropic plate having clamped-simply supported and free-free boundary conditions (i.e., C-F-S-F). Liu and Huang [16] directly extended the semi-analytical finite difference method reported in [8] to free vibrations of orthotropic plates with elastically restrained and free edges. Some eigenvalues for R-F-R-F orthotropic plates have been reported. On top of that, to the best knowledge of the authors, no exact analytical solution is currently available for transverse vibration of $\mathrm{R}-\mathrm{F}-\mathrm{R}-\mathrm{F}$ orthotropic plates.

Although approximate solutions and numerical modelling may be sufficient for practical purposes, exact solutions are desirable to assess the effectiveness of these approximate solutions. Recently, an analytical method of finite integral transforms has been extensively applied to obtained the exact series solutions of bending of plates [17-20]. By using this method, the authors [21,22] obtained the exact solutions for bending of R-R-R-R and R-F-R-F orthotropic plates with integral kernel of $\sin \alpha_{m} x \sin \beta_{n} y$ and $\sin \alpha_{m} x \cos \beta_{n} y$, respectively. However, it has been found that the formulation of the finite integral transform method used for the bending problems of orthotropic plates cannot be directly applied to vibration problems [23], which involve solving a highly non-linear equation and would be quite difficult.

In the present study, an alternative formulation of the finite integral transform method was developed for the free vibration of R-F-R-F rectangular orthotropic plates. Through a systematic solving procedure, the characteristic equation for eigenvalues can be derived. The frequency parameters and corresponding mode shapes can be obtained by solving the eigenvalue problem numerically. A convergence study and extensive comparisons with previous results were conducted to verify the accuracy and efficiency of the present method. The mode shapes of an orthotropic plate having different degrees of rotational restraints along the opposite edges were also illustrated.

\section{Formulation and Methodology}

As illustrated in Figure 1, a rectangular orthotropic thin plate is considered herein, which has two opposite edges free (i.e., $y=0$ and $y=b$ ) and the others rotationally restrained (i.e., $x=0$ and $x=a$ ). The differential equation for the free transverse vibration of orthotropic plates is [1]

$$
D_{x} \frac{\partial^{4} w}{\partial x^{4}}+2 H \frac{\partial^{4} w}{\partial x^{2} \partial y^{2}}+D_{y} \frac{\partial^{4} w}{\partial y^{4}}+\rho h \frac{\partial^{2} w}{\partial t^{2}}=0
$$

in which $w(x, y, t)$ is the displacement function; $\rho$ is the density of the plate; $D_{x}$ and $D_{y}$ are the flexural rigidity in the $x$-direction and $y$-direction, respectively; and $H$ is effective torsional rigidity.

The frequency of sinusoidal oscillations is denoted by $\omega$. Then, the displacement function of the plate $w(x, y, t)$ can be given by

$$
w(x, y, t)=W(x, y) e^{i \omega t}
$$

Substituting Equation (2) into Equation (1), it can be obtained

$$
D_{x} \frac{\partial^{4} W}{\partial x^{4}}+2 H \frac{\partial^{4} W}{\partial x^{2} \partial y^{2}}+D_{y} \frac{\partial^{4} W}{\partial y^{4}}-\omega^{2} \rho h W=0
$$


For simplicity, the partial differentiation was denoted by a comma (e.g., $\left.\frac{d w}{d x}=w, x\right)$. The boundary conditions of the plate can be written as

$$
\begin{aligned}
& w=0, M_{x}=-D_{x}\left(w_{, x x}+v_{y} w_{, y y}\right)=-R_{x 0} w_{, x} \text { at } x=0 \\
& w=0, M_{x}=-D_{x}\left(w_{, x x}+v_{y} w_{, y y}\right)=R_{x a} w_{, x} \text { at } x=a \\
& M_{y}=-D_{y}\left(w_{, y y}+v_{x} w_{, x x}\right)=0 \text { at } y=0, b \\
& V_{y}=-D_{y} w_{, y y y}-\left(H+2 D_{x y}\right) w_{, y x x}=0 \text { at } y=0, b
\end{aligned}
$$

where $M_{x}$ and $M_{y}$ are the bending moments, $V_{y}$ is the effective shear force, and $R_{x 0}$ and $R_{x a}$ are rotational stiffness as shown in Figure 1. In order to describe the rotational stiffness regarding the flexural stiffness of the plate, a rotational fixity factor $r$ was developed by Zhang and $\mathrm{Xu}$ [21] as

$$
\begin{aligned}
& r_{x 0}=\frac{1}{1+3 \frac{D_{x}}{R_{x 0} a}} \\
& r_{x a}=\frac{1}{1+3 \frac{D_{x}}{R_{x a} a}}
\end{aligned}
$$

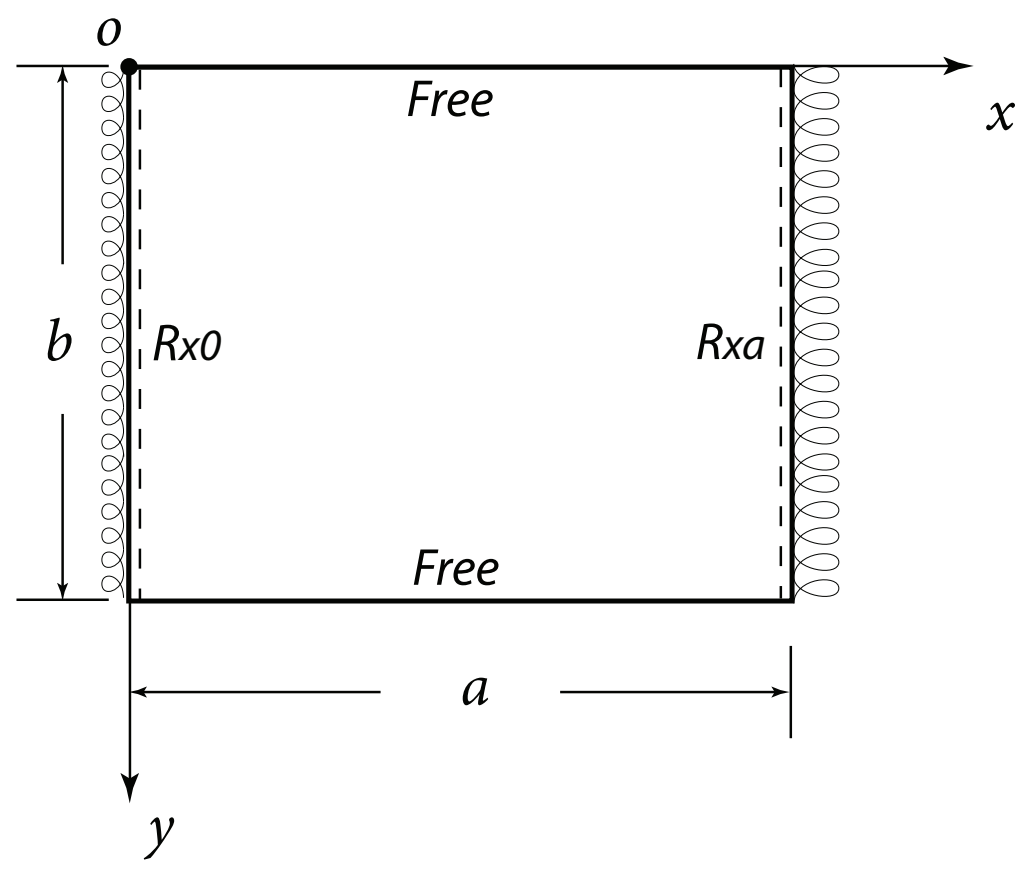

Figure 1. Orthotropic plate with opposite rotationally restrained and free edges (R-F-R-F).

Rotational fixity factors have a range from 0 to 1 . Then, a general boundary condition can be modelled by different values. For instance, the limiting cases, simply supported and fully clamped boundary conditions, will be treated as $r=0$ and $r=1$, respectively. Thus, it can be obtained from Equations (5) that

$$
\begin{aligned}
& R_{x 0} a=\frac{3 r_{x 0}}{1-r_{x 0}} D_{x} \\
& R_{x a} a=\frac{3 r_{x a}}{1-r_{x a}} D_{x}
\end{aligned}
$$


At first, the boundary conditions were rearranged by separately taking the finite cosine transform (FCT) of Equations (4a) and (4b) with respect to $y$ and the finite sine transform (FST) of Equations (4c) and (4d) with respect to $x$. As a result, the boundary conditions can be expressed as

$$
\begin{aligned}
D_{x} \hat{W}_{, x x}(0, n) & =R_{x 0} \hat{W}_{, x}(0, n) \\
D_{x} \hat{W}_{, x x}(a, n) & =-R_{x a} \hat{W}_{, x}(a, n) \\
\bar{W}_{, y y}(m, y) & =v_{x} \alpha_{m}^{2} \bar{W}(m, y), \text { for } y=0, b \\
\bar{W}_{, y y y}(m, y) & =\frac{H+2 D_{x y}}{D_{y}} \alpha_{m}^{2} \bar{W}_{, y}(m, y), \text { for } y=0, b
\end{aligned}
$$

Subsequently, the governing equation of Equation (3) is solved by using the method of finite integral transform. In this paper, the joint finite integral transform is defined by applying FST with respect to $x$ with $m$ as the subsidiary variable and the FCT in regard to $y$ with $n$.

$$
\hat{W}(m, n)=\int_{0}^{a} \int_{0}^{b} W(x, y) \sin \alpha_{m} x \cos \beta_{n} y d x d y
$$

where

$$
\alpha_{m}=\frac{m \pi}{a}, \beta_{n}=\frac{n \pi}{b}(m=1,2,3, \ldots, n=0,1,2,3, \ldots)
$$

The transform inversion of Equation (8) can be obtained as [24]

$$
W(x, y)=\frac{4}{a b} \sum_{m=1}^{\infty} \sum_{n=0}^{\infty} \varepsilon_{n} \hat{W}(m, n) \sin \alpha_{m} x \cos \beta_{n} y
$$

where

$$
\varepsilon_{n}=\left\{\begin{array}{cc}
1 / 2, & n=0 \\
1, & n \neq 0
\end{array}\right.
$$

Taking joint finite sine and cosine transforms on both sides of Equation (3), it gives

$$
\int_{0}^{a} \int_{0}^{b} \nabla_{o}^{4} W(x, y) \sin \alpha_{m} x \cos \beta_{n} y d x d y-\omega^{2} \rho h \hat{W}(m, n)=0
$$

where

$$
\nabla_{o}^{4}=D_{x} \frac{\partial^{4}}{\partial x^{4}}+2 H \frac{\partial^{4}}{\partial x^{2} \partial y^{2}}+D_{y} \frac{\partial^{4}}{\partial y^{4}}
$$


Using integration by parts and considering the boundary conditions of Equations (7), the joint finite sine and cosine transforms of the fourth derivatives in Equation (12) are given by

$$
\begin{aligned}
\int_{0}^{a} \int_{0}^{b} W_{, x x x x} \sin \alpha_{m} x \cos \beta_{n} y d x d y= & \alpha_{m}^{4} \hat{\bar{W}}(m, n) \\
& -\alpha_{m}\left[(-1)^{m} \hat{W}_{, x x}(a, n)-\hat{W}_{, x x}(0, n)\right] \\
\int_{0}^{a} \int_{0}^{b} W_{, x x y y} \sin \alpha_{m} x \cos \beta_{n} y d x d y= & \alpha_{m}^{2} \beta_{n}^{2} \hat{\bar{W}}(m, n) \\
& -\alpha_{m}^{2}\left[(-1)^{n} \bar{W}_{, y}(m, b)-\bar{W}_{, y}(m, 0)\right] \\
\int_{0}^{a} \int_{0}^{b} W_{, y y y y} \sin \alpha_{m} x \cos \beta_{n} y d x d y= & \beta_{n}^{4} \hat{W}(m, n) \\
& +\left[(-1)^{n} \bar{W}_{, y y y}(m, b)-\bar{W}_{, y y y}(m, 0)\right] \\
& -\beta_{n}^{2}\left[(-1)^{n} \bar{W}_{, y}(m, b)-\bar{W}_{, y}(m, 0)\right]
\end{aligned}
$$

in which $\hat{W}_{, x x}(0, n)$ and $\hat{W}_{, x x}(a, n)$ are determined from FCT with respect to $y$ at edges $(x=0$ and $x=a)$. Similarly, $\bar{W}_{, y}(m, 0)$ and $\bar{W}_{, y}(m, b)$ are obtained from two free edges by FST. They are expressed as

$$
\begin{aligned}
& \hat{W}_{, x x}(0, n)=\int_{0}^{b} W_{, x x}(0, y) \cos \beta_{n} y d y \\
& \hat{W}_{, x x}(a, n)=\int_{0}^{b} W_{, x x}(a, y) \cos \beta_{n} y d y \\
& \bar{W}_{, y y}(m, 0)=\int_{0}^{a} W_{, x x}(x, 0) \sin \beta_{n} x d x \\
& \bar{W}_{, y y}(m, b)=\int_{0}^{a} W_{, x x}(x, b) \sin \beta_{n} x d x
\end{aligned}
$$

It can be obtained from Equation (7d) that

$$
\left[(-1)^{n} \bar{W}_{, y y y}(m, b)-\bar{W}_{, y y y}(m, 0)\right]=\frac{H+2 D_{x y}}{D_{y}} \alpha_{m}^{2}\left[(-1)^{n} \bar{W}_{, y}(m, b)-\bar{W}_{, y}(m, 0)\right]
$$

Substituting Equation (16) into Equation (14c) yields

$$
\begin{aligned}
& \int_{0}^{a} \int_{0}^{b} W_{, y y y y} \sin \alpha_{m} x \cos \beta_{n} y d x d y \\
= & \beta_{n}^{4} \hat{W}(m, n)+\left[\frac{H+2 D_{x y}}{D_{y}} \alpha_{m}^{2}-\beta_{n}^{2}\right]\left[(-1)^{n} \bar{W}_{, y}(m, b)-\bar{W}_{, y}(m, 0)\right]
\end{aligned}
$$

Then, substituting Equations (14a), (14b) and (17) into Equation (12) yields

$$
\begin{aligned}
\hat{W}(m, n)= & \frac{1}{\Omega_{m n}-\omega^{2} \rho h}\left\{\alpha_{m} D_{x}\left[(-1)^{m} \hat{W}_{, x x}(a, n)-\hat{W}_{, x x}(0, n)\right]\right. \\
& \left.+D_{y}\left(v_{x} \alpha_{m}^{2}+\beta_{n}^{2}\right)\left[(-1)^{n} \bar{W}_{, y}(m, b)-\bar{W}_{, y}(m, 0)\right]\right\}
\end{aligned}
$$


where

$$
\Omega_{m n}=D_{x} \alpha_{m}^{4}+2 H \alpha_{m}^{2} \beta_{n}^{2}+D_{y} \beta_{n}^{4}
$$

Taking the inverse FCT of Equation (18), it is obtained

$$
\bar{w}(m, y)=\frac{2}{b} \sum_{n=0}^{\infty} \varepsilon_{n} \hat{\bar{w}}(m, n) \cos \beta_{n} y
$$

Taking second-order derivative of Equation (20) with respect to $y$ and applying the Stokes' transformation [25] gives

$$
\bar{w}_{, y y}(m, y)=\frac{2}{b} \sum_{n=0}^{\infty} \varepsilon_{n}\left\{\left[(-1)^{n} \bar{w}_{, y}(m, b)-\bar{w}_{, y}(m, 0)\right]-\beta_{n}^{2} \hat{\bar{w}}(m, n)\right\} \cos \beta_{n} y
$$

Substituting Equations (7c) and (20) into Equation (21) gives

$$
\begin{aligned}
& \sum_{n=0}^{\infty} \varepsilon_{n}\left\{\left[(-1)^{n} \bar{w}_{, y}(m, b)-\bar{w}, y(m, 0)\right]-\left(v_{x} \alpha_{m}^{2}+\beta_{n}^{2}\right) \hat{\bar{w}}(m, n)\right\}=0 \\
& \sum_{n=0}^{\infty}(-1)^{n} \varepsilon_{n}\left\{\left[(-1)^{n} \bar{w}_{, y}(m, b)-\bar{w}_{, y}(m, 0)\right]-\left(v_{x} \alpha_{m}^{2}+\beta_{n}^{2}\right) \hat{\hat{w}}(m, n)\right\}=0
\end{aligned}
$$

For numerical calculations, the infinite series in Equation (22) should be truncated to be finite terms, $N$. Then, it can be obtained expressions for $\bar{w}_{, y}(m, 0)$ and $\bar{w}, y(m, b)$ by solving Equation (22). They are expressed as

$$
\begin{aligned}
& \bar{w}_{, y}(m, 0)=\sum_{n=0}^{N} \frac{(-1)^{n+N}-(2 N+1)}{2 N(N+1)} \varepsilon_{n}\left(v_{x} \alpha_{m}^{2}+\beta_{n}^{2}\right) \hat{\bar{w}}(m, n) \\
& \bar{w}, y(m, b)=\sum_{n=0}^{N} \frac{(-1)^{n}(2 N+1)-(-1)^{N}}{2 N(N+1)} \varepsilon_{n}\left(v_{x} \alpha_{m}^{2}+\beta_{n}^{2}\right) \hat{\bar{w}}(m, n)
\end{aligned}
$$

Then, taking the inverse finite sine transform of Equation (18) with respect to $x$ yields

$$
\hat{w}(x, n)=\frac{2}{a} \sum_{m=1}^{\infty} \hat{w}(m, n) \sin \alpha_{m} x
$$

Taking the derivative of Equation (24) with respect to $x$ and using Stokes's transformation [25], it is found

$$
\hat{w}_{, x}(x, n)=\frac{2}{a} \sum_{m=1}^{\infty} \alpha_{m} \hat{\bar{w}}(m, n) \cos \alpha_{m} x
$$

Substituting Equations (7a) and (7b) into Equation (25) and replacing constants $R_{x 0}$ and $R_{x a}$ by the corresponding rotational fixity factors $r_{x 0}$ and $r_{x a}$ based in Equations (6), it yields

$$
\begin{aligned}
& \hat{w}_{, x x}(0, n)=\frac{6 r_{x 0}}{a^{2}\left(1-r_{x 0}\right)} \sum_{m=1}^{\infty} \alpha_{m} \hat{\hat{w}}(m, n) \\
& \hat{w}_{, x x}(a, n)=\frac{-6 r_{x a}}{a^{2}\left(1-r_{x a}\right)} \sum_{m=1}^{\infty}(-1)^{m} \alpha_{m} \hat{\bar{w}}(m, n)
\end{aligned}
$$


At last, substituting expressions of $\hat{w}, x x(0, n), \hat{w}, x x(a, n), \bar{w}, y(m, 0)$ and $\bar{w}_{, y}(m, b)$ in Equations (23) and Equations (26) into Equation (18), it yields

$$
\begin{aligned}
& \Omega_{m n} \hat{W}(m, n)+\frac{2 \alpha_{m} D_{x}}{a^{2}} \sum_{i=1}^{M}\left[(-1)^{i+m} \frac{3 r_{x a}}{1-r_{x a}}+\frac{3 r_{x 0}}{1-r_{x 0}}\right] \alpha_{i} \hat{W}(i, n) \\
& +D_{y}\left(v_{x} \alpha_{m}^{2}+\beta_{n}^{2}\right) \sum_{j=0}^{N} \frac{(-1)^{n+N}+(-1)^{j+N}-\left[(-1)^{j+n}+1\right](2 N+1)}{2 N(N+1)} \varepsilon_{j}\left(v_{x} \alpha_{m}^{2}+\beta_{j}^{2}\right) \hat{W}(m, j) \\
& =\omega^{2} \rho h \hat{W}(m, n)
\end{aligned}
$$

It can be found that Equation (27) is different from formulations for the bending problems of plates which were presented in [21,22]. If adopting the formulations for bending problems, frequencies should be acquired by solving a highly nonlinear equation which would be quite difficult. However, the present Equation (27) is an eigenvalue problem which is much easier to solve.

It should be noted that all the series expansions are truncated herein to finite number $M$ for $m$ and $N$ for $n$ while the upper limit of summation is theoretically specified as infinity. For each combination of $M$ and $N$, Equation (27) produces $M \times(N+1)$ equations with $M \times(N+1)$ unknown coefficients. Equation (27) can be expressed in the matrix form as follows:

$$
\mathbf{A W}=\omega^{2} \rho h \mathbf{W}
$$

where $\mathbf{W}=[\hat{\mathrm{W}}(1,1), \hat{W}(1,2) \ldots \hat{\hat{W}}(1, N), \hat{\hat{W}}(2,1) \ldots \hat{\bar{W}}(2, N) \ldots \hat{\bar{W}}(M, N)]$ and $\mathbf{A}$ is the corresponding coefficient matrix which can be obtained form the left hand side of Equation (27). Equation (28) is a standard characteristic equation for a matrix and the corresponding eigenfrequencies $\omega$ can be conveniently obtained. For each eigenfrequency, the corresponding eigenvector can be directly determined by substituting the eigenfrequency into Equation (28). Consequently, the related mode shape can be developed by substituting the eigenvector of $\hat{W}(m, n)$ into Equation (10) for each $\omega$.

In addition, the solution can be easily determined for a plate with two opposite edges simply supported and the others free (S-F-S-F) by setting $r_{x 0}=r_{x a}=0$. Moreover, For a plate with opposite edges fully clamped and the others free $(\mathrm{C}-\mathrm{F}-\mathrm{C}-\mathrm{F})$, the corresponding rotational fixity factors are equal to 1 . In this research, such boundary conditions can be approximately evaluated by setting rotational fixity factors approaching to 1 (e.g., 0.9999) to avoid the singularity problem of Equation (6).

\section{Numerical Results}

In this section, extensive numerical studies have been conducted to validate the present method through solving the eigenvalue problem of Equation (28) numerically by using MATLAB. For convenience, the numbers of double series terms are assumed to be the same and denoted by $N$ (i.e., $m=1,2,3, \ldots, N, n=0,1,2,3, \ldots, N$ ) and the two restrained edges have the same rotational fixity factor (i.e., $r_{x 0}=r_{x a}=r$ ). It should be noted that the series solutions obtained by the present method are theoretically convergent to the exact values when $N \rightarrow \infty$ while solutions with desired accuracy can be determined by finite terms.

First of all, the convergence of the fundamental frequency parameter is shown in Figure 2 for the case of a square R-F-R-F isotropic plate with $r=0.5$. The values are examined by truncating the series up to $N=160$ since the computation time becomes very long on a standard personal computer when $N>160$. From the results of the convergence study, the number of series terms $N$ is taken to be 100 for all numerical results presented herein. 


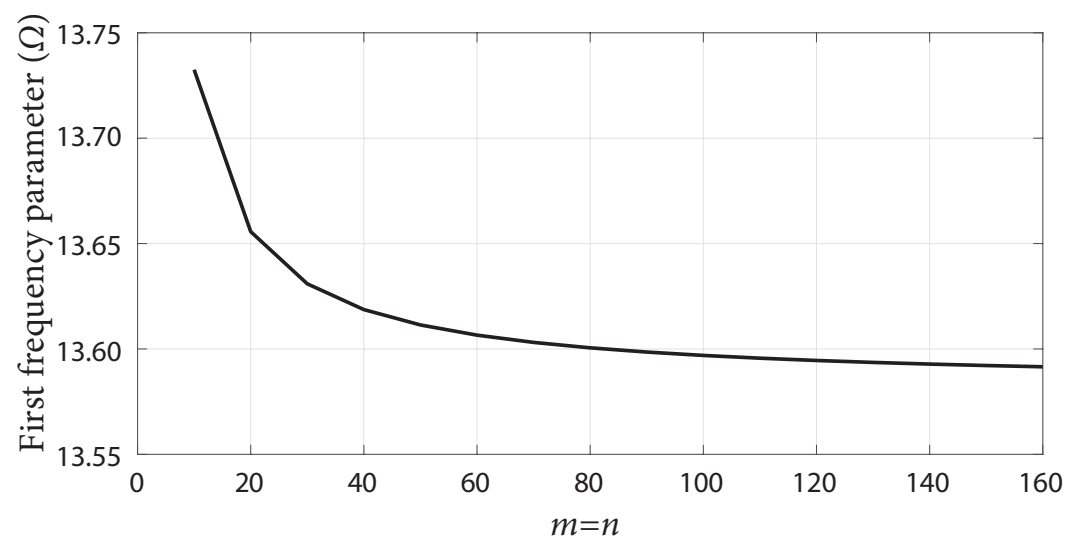

Figure 2. Convergence of the fundamental frequency parameter $\Omega=\omega a^{2} \sqrt{\rho h / D}$ of a square isotropic plate with $r=0.5$.

Since the results of natural frequency of R-F-R-F plates are limited, the present method was first used to obtain the frequencies of simply supported plates and fully clamped plates. Two boundary conditions have been numerically computed and results are presented in Tables 1 and 2: (1) two opposite edges $(x=0$ and $x=a)$ simply supported and the other two $(y=0$ and $y=b)$ free (i.e., S-F-S-F); and (2) two opposite edges $(x=0$ and $x=a)$ fully clamped and the other two $(y=0$ and $y=b$ ) free (i.e., $\mathrm{C}-\mathrm{F}-\mathrm{C}-\mathrm{F}$ ). As mentioned before, these two cases can be treated as two limit cases with rotational fixity factors, $r=0$ and $r=1$, respectively. It should be noted that $r \neq 1$ in Equation (27) and thus C-F-C-F is simulated by setting $r=0.9999$ in this study. Table 1 tabulates the first six frequency parameters $\Omega=\omega a^{2} \sqrt{\rho h / D}$ of isotropic plates. Results for orthotropic square plates are illustrated in Table 2. Different aspect ratios were investigated. Excellent agreements can be found from comparisons between the present predictions and previously published results for $r=0$ and $r=0.9999$ (i.e., S-F-S-F and C-F-C-F), respectively. Additionally, results for R-F-R-F plates with $r=0.5$ are also provided for future comparisons.

Table 1. First six frequency parameters $\Omega=\omega a^{2} \sqrt{\rho h / D}$ for isotropic plates with three different rotational fixity factors $(v=0.3)$.

\begin{tabular}{|c|c|c|c|c|c|c|c|c|}
\hline \multirow{2}{*}{$r$} & \multirow{2}{*}{$b / a$} & \multirow{2}{*}{ Results } & \multicolumn{6}{|c|}{ Mode } \\
\hline & & & 1 & 2 & 3 & 4 & 5 & 6 \\
\hline \multirow{10}{*}{0} & \multirow{3}{*}{0.5} & [26] & 9.88 & 27.6 & 39.48 & 64.88 & 88.84 & 105.56 \\
\hline & & [27] & 9.87 & 27.52 & 39.48 & 64.54 & 88.83 & 105.48 \\
\hline & & present & 9.5114 & 27.4730 & 38.5184 & 64.4515 & 87.2662 & 105.4009 \\
\hline & \multirow{4}{*}{1} & [26] & 9.87 & 16.22 & 36.82 & 39.48 & 47.14 & 71.33 \\
\hline & & [27] & 9.87 & 16.13 & 36.71 & 39.48 & 46.73 & 70.73 \\
\hline & & [28] & 9.6314 & 16.1348 & 36.7256 & 38.9450 & 46.7381 & 70.7401 \\
\hline & & present & 9.6296 & 16.1129 & 36.6655 & 38.9360 & 46.6979 & 70.6287 \\
\hline & \multirow{3}{*}{2} & [26] & 9.87 & 11.79 & 17.83 & 27.91 & 39.48 & 41.53 \\
\hline & & [27] & 9.87 & 11.66 & 17.66 & 27.73 & 39.48 & 41.18 \\
\hline & & present & 9.7340 & 11.6745 & 17.6572 & 27.7048 & 39.1773 & 41.1702 \\
\hline \multirow{3}{*}{0.5} & 0.5 & present & 13.5055 & 29.1960 & 43.3384 & 67.5191 & 92.4649 & 105.8957 \\
\hline & 1 & present & 13.5969 & 18.8036 & 37.9805 & 43.7159 & 50.7794 & 73.4469 \\
\hline & 2 & present & 13.6752 & 15.1321 & 20.1497 & 29.3911 & 43.4613 & 43.9340 \\
\hline \multirow{7}{*}{0.9999} & \multirow{2}{*}{0.5} & [26] & 22.39 & 36.46 & 61.69 & 83.03 & 110.9 & 120.9 \\
\hline & & present & 22.2067 & 36.0988 & 61.2502 & 82.7627 & 109.5111 & 120.3845 \\
\hline & \multirow{3}{*}{1} & [26] & 22.39 & 26.61 & 44.13 & 61.69 & 67.66 & 80.76 \\
\hline & & [28] & 22.272 & 26.529 & 43.664 & 61.466 & 67.549 & 79.904 \\
\hline & & present & 22.3421 & 26.5631 & 43.7064 & 61.6519 & 67.6178 & 79.8786 \\
\hline & \multirow[b]{2}{*}{2} & [26] & 22.39 & 23.51 & 27.72 & 35.96 & 49.02 & 61.69 \\
\hline & & present & 22.4337 & 23.5357 & 27.6433 & 35.6897 & 48.6187 & 61.8753 \\
\hline
\end{tabular}


Table 2. First six frequency parameters $\Omega=\omega a^{2} \sqrt{\rho h / D_{x}}$ for orthotropic square plates $(b / a=1)$ with three different rotational fixity factors.

\begin{tabular}{|c|c|c|c|c|c|c|c|c|c|c|}
\hline \multirow{2}{*}{$r$} & \multirow{2}{*}{$D_{x} / D_{y}$} & \multirow{2}{*}{$H / D_{y}$} & \multirow{2}{*}{$v_{x}$} & \multirow{2}{*}{ Results } & \multicolumn{6}{|c|}{ Mode } \\
\hline & & & & & 1 & 2 & 3 & 4 & 5 & 6 \\
\hline \multirow{6}{*}{0} & \multirow{6}{*}{0.5} & \multirow{2}{*}{0.5} & \multirow{2}{*}{0.3} & [29] & 9.1507 & 13.511 & 37.46 & 40.4704 & 42.3718 & 68.5419 \\
\hline & & & & present & 9.1484 & 13.4905 & 37.4421 & 40.4343 & 42.3186 & 68.4430 \\
\hline & & \multirow{2}{*}{1} & \multirow{2}{*}{0.3} & [29] & 9.3871 & 20.5731 & 38.404 & 50.9914 & 53.0128 & 87.1387 \\
\hline & & & & present & 9.3835 & 20.5387 & 38.3858 & 50.9049 & 52.9419 & 87.0934 \\
\hline & & \multirow{2}{*}{2} & \multirow{2}{*}{0.3} & [29] & 9.55 & 29.4576 & 38.8208 & 66.6428 & 67.3417 & 87.8272 \\
\hline & & & & present & 9.5461 & 29.4211 & 38.8042 & 66.5191 & 67.2802 & 87.7881 \\
\hline 0.5 & 0.5 & 2 & 0.3 & present & 13.5354 & 31.0445 & 43.5971 & 67.3021 & 70.2325 & 92.9605 \\
\hline \multirow{2}{*}{0.9999} & \multirow{2}{*}{14.5454} & \multirow{2}{*}{0.9644} & \multirow{2}{*}{0.24} & [30] & 22.369 & 22.695 & 24.49 & 30.2 & 42.1 & 60.49 \\
\hline & & & & present & 22.5461 & 22.8694 & 24.6502 & 30.3287 & 42.1714 & 60.5361 \\
\hline
\end{tabular}

Furthermore, considerable numerical results have been obtained for R-F-R-F orthotropic plates and compared with existing results reported by Liu and Huang [16]. In the work of [16], five different flexural properties and two different aspect ratios were investigated. In particular, three different degrees of rotational restraints were studied, which was described by the parameter of $\Phi=D_{x} / R a$. Consequently, the corresponding rotational fixity factor in Equation (5) can be expressed by

$$
r=\frac{1}{1+3 \Phi}
$$

Extensive comparisons are illustrated in Tables 3 and 4 and excellent agreement can be observed. However, it can be found that results of [16] for most results of $\Phi=0.1$ are lower than the present results, which were denoted in bold. Such findings were also reported by Liu and Huang in [16] when comparing their results of $\mathrm{C}-\mathrm{C}-\mathrm{C}-\mathrm{C}$ and $\mathrm{C}-\mathrm{C}-\mathrm{C}-\mathrm{F}$ plates with others.

Table 3. First six frequency parameters $\Omega=\omega a^{2} \sqrt{\rho h / H}$ for orthotropic plates with various flexural stiffness and different rotational fixity factors $\left(D_{y} / H=1, v=0.3\right.$, and $\left.a / b=1\right)$.

\begin{tabular}{|c|c|c|c|c|c|c|c|c|c|}
\hline \multirow{2}{*}{$D_{x} / H$} & \multirow{2}{*}{$\Phi$} & \multirow{2}{*}{$r$} & \multirow{2}{*}{ Results } & \multicolumn{6}{|c|}{ Mode } \\
\hline & & & & 1 & 2 & 3 & 4 & 5 & 6 \\
\hline \multirow{6}{*}{1} & \multirow{2}{*}{0.01} & \multirow{2}{*}{0.97087} & [16] & 21.476 & 25.914 & 43.323 & 59.327 & 65.800 & 80.462 \\
\hline & & & present & 21.495 & 25.712 & 42.896 & 59.356 & 65.331 & 79.174 \\
\hline & \multirow{2}{*}{0.1} & \multirow{2}{*}{0.76923} & {$[16]$} & 17.192 & 21.908 & 40.141 & 49.776 & 56.630 & 78.336 \\
\hline & & & present & 17.157 & 21.686 & 39.721 & 49.607 & 56.055 & 76.882 \\
\hline & \multirow{2}{*}{10000} & \multirow{2}{*}{0.00003} & [16] & 9.678 & 16.302 & 37.026 & 39.143 & 47.228 & 72.508 \\
\hline & & & present & 9.630 & 16.113 & 36.666 & 38.936 & 46.698 & 70.629 \\
\hline \multirow{6}{*}{1.5} & \multirow{2}{*}{0.01} & \multirow{2}{*}{0.97087} & [16] & 26.373 & 30.161 & 46.075 & 72.836 & 78.355 & 81.195 \\
\hline & & & present & 26.742 & 30.281 & 45.946 & 73.780 & 78.720 & 81.058 \\
\hline & \multirow{2}{*}{0.1} & \multirow{2}{*}{0.76923} & {$[16]$} & 21.112 & 25.159 & 42.051 & 61.145 & 66.971 & 78.812 \\
\hline & & & present & 22.501 & 26.206 & 42.548 & 63.752 & 68.960 & 78.524 \\
\hline & \multirow{2}{*}{10000} & \multirow{2}{*}{0.00003} & [16] & 11.952 & 17.768 & 37.700 & 48.164 & 55.034 & 76.631 \\
\hline & & & present & 11.893 & 17.560 & 37.324 & 47.909 & 54.406 & 75.520 \\
\hline \multirow{6}{*}{2} & \multirow{2}{*}{0.01} & \multirow{2}{*}{0.97087} & [16] & 30.494 & 33.877 & 48.647 & 82.683 & 84.205 & 89.170 \\
\hline & & & present & 31.127 & 34.237 & 48.733 & 82.787 & 85.849 & 90.154 \\
\hline & \multirow{2}{*}{0.1} & \multirow{2}{*}{0.76923} & [16] & 24.428 & 28.034 & 43.865 & 70.707 & 75.917 & 79.278 \\
\hline & & & present & 27.062 & 30.272 & 45.315 & 75.934 & 80.192 & 80.409 \\
\hline & \multirow{2}{*}{10000} & \multirow{2}{*}{0.00003} & [16] & 13.858 & 19.121 & 38.362 & 55.742 & 61.681 & 77.413 \\
\hline & & & present & 13.790 & 18.896 & 37.971 & 55.449 & 61.150 & 75.842 \\
\hline
\end{tabular}


Table 3. Cont.

\begin{tabular}{|c|c|c|c|c|c|c|c|c|c|}
\hline \multirow{2}{*}{$D_{x} / H$} & \multirow{2}{*}{$\Phi$} & \multirow{2}{*}{$r$} & \multirow{2}{*}{ Results } & \multicolumn{6}{|c|}{ Mode } \\
\hline & & & & 1 & 2 & 3 & 4 & 5 & 6 \\
\hline \multirow{6}{*}{2.5} & \multirow{2}{*}{0.01} & \multirow{2}{*}{0.97087} & [16] & 34.120 & 37.223 & 51.078 & 84.182 & 94.212 & 98.824 \\
\hline & & & present & 34.971 & 37.777 & 51.337 & 84.426 & 96.432 & 100.298 \\
\hline & \multirow{2}{*}{0.1} & \multirow{2}{*}{0.76923} & [16] & 27.338 & 30.640 & 45.603 & 79.122 & 80.206 & 83.922 \\
\hline & & & present & 31.090 & 33.962 & 47.974 & 81.840 & 86.763 & 90.744 \\
\hline & \multirow{2}{*}{10000} & \multirow{2}{*}{0.00003} & [16] & 15.532 & 20.385 & 39.013 & 62.406 & 68.005 & 76.640 \\
\hline & & & present & 15.455 & 20.144 & 38.607 & 62.080 & 67.221 & 76.162 \\
\hline \multirow{6}{*}{3} & \multirow{2}{*}{0.01} & \multirow{2}{*}{0.97087} & [16] & 37.396 & 40.291 & 53.393 & 85.647 & 103.258 & 107.638 \\
\hline & & & present & 38.433 & 41.011 & 53.797 & 86.002 & 105.969 & 109.509 \\
\hline & \multirow{2}{*}{0.1} & \multirow{2}{*}{0.76923} & [16] & 29.965 & 33.040 & 47.273 & 81.178 & 86.745 & 91.235 \\
\hline & & & present & 34.726 & 37.349 & 50.517 & 83.453 & 96.588 & 100.209 \\
\hline & \multirow{2}{*}{10000} & \multirow{2}{*}{0.00003} & [16] & 17.012 & 21.574 & 39.654 & 68.423 & 73.641 & 76.745 \\
\hline & & & present & 16.958 & 21.318 & 39.233 & 68.068 & 72.787 & 76.481 \\
\hline \multirow{6}{*}{3.5} & \multirow{2}{*}{0.01} & \multirow{2}{*}{0.97087} & [16] & 40.407 & 43.141 & 55.607 & 87.079 & 111.564 & 115.745 \\
\hline & & & present & 41.610 & 44.007 & 56.140 & 87.530 & 114.720 & 118.004 \\
\hline & \multirow{2}{*}{0.1} & \multirow{2}{*}{0.76923} & [16] & 32.380 & 35.277 & 48.884 & 82.144 & 93.714 & 98.015 \\
\hline & & & present & 38.060 & 40.490 & 52.951 & 85.030 & 105.631 & 108.976 \\
\hline & \multirow{2}{*}{10000} & \multirow{2}{*}{0.00003} & [16] & 18.428 & 22.701 & 40.284 & 73.593 & 77.026 & 78.877 \\
\hline & & & present & 18.338 & 22.432 & 39.849 & 73.570 & 76.799 & 77.957 \\
\hline
\end{tabular}

Table 4. First six frequency parameters $\Omega=\omega a^{2} \sqrt{\rho h / H}$ for orthotropic plates with various flexural stiffness and different rotational fixity factors $\left(D_{y} / H=1, v=0.3\right.$, and $\left.a / b=0.5\right)$ ).

\begin{tabular}{|c|c|c|c|c|c|c|c|c|c|}
\hline \multirow{2}{*}{$D_{x} / H$} & \multirow{2}{*}{$\Phi$} & \multirow{2}{*}{$r$} & \multirow{2}{*}{ Results } & \multicolumn{6}{|c|}{ Mode } \\
\hline & & & & 1 & 2 & 3 & 4 & 5 & 6 \\
\hline \multirow{6}{*}{1} & \multirow{2}{*}{0.01} & \multirow{2}{*}{0.97087} & [16] & 21.357 & 35.537 & 58.967 & 81.294 & 109.976 & 115.987 \\
\hline & & & present & 21.366 & 35.170 & 58.966 & 80.416 & 108.770 & 115.971 \\
\hline & \multirow{2}{*}{0.1} & \multirow{2}{*}{0.76923} & [16] & 17.094 & 31.760 & 49.427 & 72.700 & 100.455 & 107.749 \\
\hline & & & present & 17.060 & 31.389 & 49.249 & 71.823 & 100.058 & 106.691 \\
\hline & \multirow{2}{*}{10000} & \multirow{2}{*}{0.00003} & [16] & 9.570 & 27.810 & 38.712 & 65.210 & 87.729 & 106.456 \\
\hline & & & present & 9.512 & 27.473 & 38.519 & 64.452 & 87.266 & 105.401 \\
\hline \multirow{6}{*}{1.5} & \multirow{2}{*}{0.01} & \multirow{2}{*}{0.97087} & [16] & 26.279 & 38.807 & 72.541 & 91.761 & 111.206 & 142.856 \\
\hline & & & present & 26.637 & 38.797 & 73.461 & 91.802 & 110.322 & 144.289 \\
\hline & \multirow{2}{*}{0.1} & \multirow{2}{*}{0.76923} & [16] & 21.051 & 34.121 & 60.857 & 81.023 & 108.491 & 123.765 \\
\hline & & & present & 22.418 & 34.861 & 63.462 & 82.477 & 107.974 & 127.221 \\
\hline & \multirow{2}{*}{10000} & \multirow{2}{*}{0.00003} & [16] & 11.866 & 28.692 & 47.810 & 71.071 & 106.570 & 108.108 \\
\hline & & & present & 11.798 & 28.346 & 47.571 & 70.237 & 105.632 & 107.520 \\
\hline \multirow{6}{*}{2} & \multirow{2}{*}{0.01} & \multirow{2}{*}{0.97087} & [16] & 30.412 & 41.798 & 83.941 & 101.146 & 112.381 & 165.514 \\
\hline & & & present & 31.037 & 42.042 & 85.572 & 101.866 & 111.714 & 167.983 \\
\hline & \multirow{2}{*}{0.1} & \multirow{2}{*}{0.76923} & [16] & 24.370 & 36.315 & 70.446 & 88.559 & 109.239 & 143.418 \\
\hline & & & present & 26.989 & 38.162 & 75.681 & 92.409 & 109.298 & 150.643 \\
\hline & \multirow{2}{*}{10000} & \multirow{2}{*}{0.00003} & [16] & 13.753 & 29.538 & 55.431 & 76.482 & 106.800 & 125.350 \\
\hline & & & present & 13.707 & 29.192 & 55.157 & 75.582 & 105.862 & 124.522 \\
\hline \multirow{6}{*}{2.5} & \multirow{2}{*}{0.01} & \multirow{2}{*}{0.97087} & [16] & 34.046 & 44.576 & 93.972 & 109.733 & 113.520 & 184.433 \\
\hline & & & present & 34.890 & 45.022 & 96.185 & 110.996 & 113.017 & 175.721 \\
\hline & \multirow{2}{*}{0.1} & \multirow{2}{*}{0.76923} & [16] & 27.268 & 38.364 & 78.885 & 95.905 & 109.972 & 160.741 \\
\hline & & & present & 31.022 & 41.261 & 86.535 & 101.642 & 110.610 & 167.809 \\
\hline & 10000 & ค & [16] & 15.439 & 30.372 & 62.126 & 81.537 & 107.033 & 140.538 \\
\hline & 10000 & 0.00003 & present & 15.382 & 30.015 & 61.819 & 80.572 & 106.092 & 139.466 \\
\hline
\end{tabular}


Table 4. Cont

\begin{tabular}{|c|c|c|c|c|c|c|c|c|c|}
\hline \multirow{2}{*}{$D_{x} / H$} & \multirow{2}{*}{$\Phi$} & \multirow{2}{*}{$r$} & \multirow{2}{*}{ Results } & \multicolumn{6}{|c|}{ Mode } \\
\hline & & & & 1 & 2 & 3 & 4 & 5 & 6 \\
\hline \multirow{6}{*}{3} & \multirow{2}{*}{0.01} & \multirow{2}{*}{0.97087} & [16] & 37.329 & 47.184 & 103.032 & 114.635 & 117.697 & 193.554 \\
\hline & & & present & 38.361 & 47.801 & 105.744 & 114.263 & 119.417 & 181.325 \\
\hline & \multirow{2}{*}{0.1} & \multirow{2}{*}{0.76923} & [16] & 29.901 & 40.317 & 86.506 & 101.984 & 110.698 & 175.531 \\
\hline & & & present & 34.663 & 44.176 & 96.379 & 110.262 & 111.896 & 173.447 \\
\hline & \multirow{2}{*}{10000} & \multirow{2}{*}{0.00003} & [16] & 16.956 & 31.180 & 68.166 & 86.296 & 107.266 & 154.272 \\
\hline & & & present & 16.891 & 30.816 & 67.830 & 85.271 & 106.321 & 152.957 \\
\hline \multirow{6}{*}{3.5} & \multirow{2}{*}{0.01} & \multirow{2}{*}{0.97087} & [16] & 40.345 & 49.653 & 111.351 & 115.728 & 125.250 & 190.216 \\
\hline & & & present & 41.543 & 50.418 & 114.511 & 115.467 & 127.275 & 186.716 \\
\hline & \multirow{2}{*}{0.1} & \multirow{2}{*}{0.76923} & [16] & 32.326 & 42.179 & 93.507 & 108.072 & 111.416 & 183.912 \\
\hline & & & present & 38.001 & 46.927 & 105.437 & 113.152 & 118.355 & 178.938 \\
\hline & \multirow{2}{*}{10000} & \multirow{2}{*}{0.00003} & [16] & 18.353 & 31.977 & 73.713 & 90.806 & 107.501 & 166.512 \\
\hline & & & present & 18.277 & 31.596 & 73.350 & 89.725 & 106.550 & 159.394 \\
\hline
\end{tabular}

At last, the influence of different degrees of rotational restraints on the mode shapes was investigated. Figure 3 shows the first, second and third mode shapes of R-F-R-F orthotropic square plates with three different values of rotational fixity factors $(0,0.5$ and 0.9999$)$. The mode shapes can be found to be significantly altered by the rotational restraints.
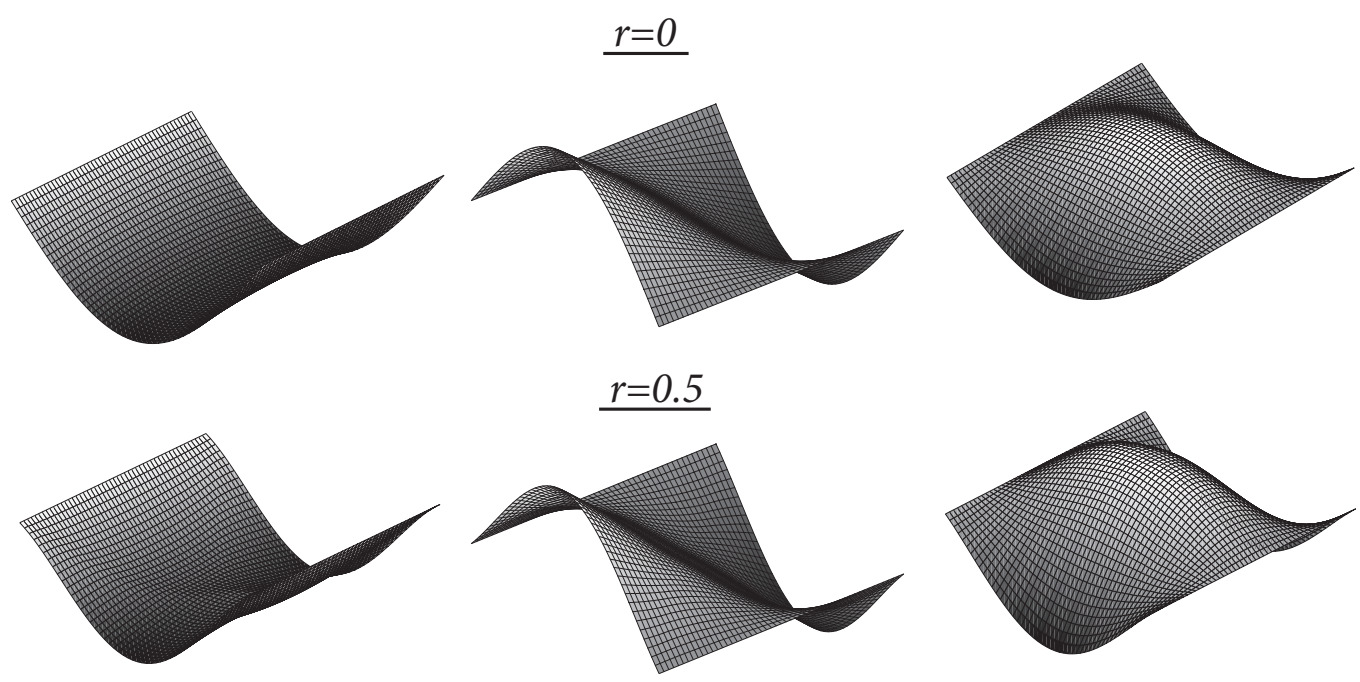

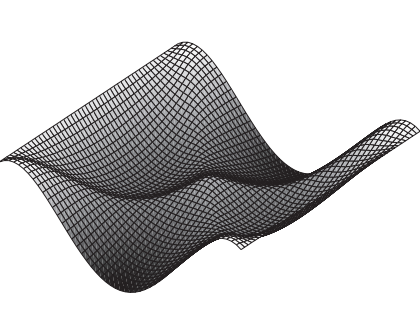

(a) first mode

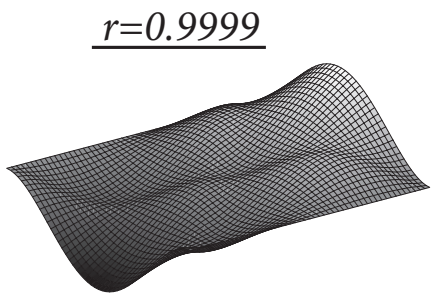

(b) Second mode

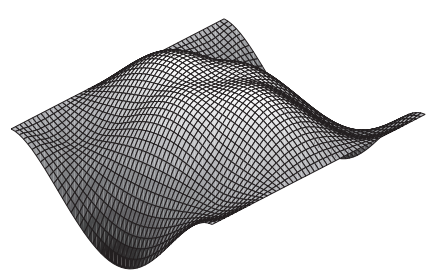

(c) third mode

Figure 3. Mode shapes of a square orthotropic plate with different rotational restraints. (a) first mode; (b) second mode; (c) third mode. 


\section{Conclusions}

In the present paper, an exact series solution for free vibration of a rectangular orthotropic plate with opposite rotationally restrained and free edges was obtained by using the finite integral transform method. A new alternative formulation was developed for the application of such a method to the transverse vibration of plates. In contrast to the formulation used for the flexural deformation of plates, a much easier eigenvalue solution can be obtained without solving a highly non-linear equation. Extensive numerical studies have been conducted to validate the present method for plates with different structural properties, rotational restraints and aspect ratios. Comparisons with existing results indicate excellent accuracy and efficiency of the present method. The mode shapes are found to be altered significantly by the rotational restraints. The merits of the present method are that the method is simple and straightforward and can be calculated with the desired accuracy.

Author Contributions: Y.Z. contributed to formal analysis in addition to writing, reviewing and editing of the final article. S.Z. was involved in the conceptualization, methodology and reviewing and editing of the final article.

Funding: This research received no external funding.

Conflicts of Interest: The authors declare no conflict of interest. The funding sponsors had no role in the design of the study; in the collection, analyses, or interpretation of data; in the writing of the manuscript, and in the decision to publish the results.

\section{References}

1. Leissa, A.W. Vibration of Plates; NASA SP-160; National Aeronautics and Space Administration: Washington, DC, USA, 1969.

2. Soedel, W. Vibrations of Shells and Plates; CRC Press: Boca Raton, FL, USA, 2004.

3. Szilard, R. Theories and Applications of Plate Analysis: Classical, Numerical and Engineering Methods; John Wiley \& Sons: Hoboken, NJ, USA, 2004.

4. Wang, C.Y.; Wang, C.M. Structural Vibration: Exact Solutions for Strings, Membranes, Beams, and Plates; CRC Press: Boca Raton, FL, USA, 2016.

5. Hoppmann, W.H., II; Greenspon, J. Flexural Vibration of a Plate with Elastic Rotational Constraint on Boundary; Technical Report 8; Department of Mechanical Engineering, The Johns Hopkins University: Baltimore, MD, USA, 1953.

6. Carmichael, T. The vibration of a rectangular plate with edges elastically restrained against rotation. Q.J. Mech. Appl. Math. 1959, 12, 29-42. [CrossRef]

7. Laura, P.; Luisoni, L.; Filipich, C. A note on the determination of the fundamental frequency of vibration of thin, rectangular plates with edges possessing different rotational flexibility coefficients. J. Sound Vib. 1977, 55, 327-333. [CrossRef]

8. Mukhopadhyay, M. Free vibration of rectangular plates with edges having different degrees of rotational restraint. J. Sound Vib. 1979, 67, 459-468. [CrossRef]

9. Laura, P.; Grossi, R. Transverse vibrations of rectangular plates with edges elastically restrained against translation and rotation. J. Sound Vib. 1981, 75, 101-107. [CrossRef]

10. Warburton, G.; Edney, S. Vibrations of rectangular plates with elastically restrained edges. J. Sound Vib. 1984, 95, 537-552. [CrossRef]

11. Zhou, D. An approximate solution of eigen-frequencies of transverse vibration of rectangular plates with elastical restraints. Appl. Math. Mech. 1996, 17, 451-456.

12. Laura, P.; Grossi, R. Transverse vibration of a rectangular plate elastically restrained against rotation along three edges and free on the fourth edge. J. Sound Vib. 1978, 59, 355-368. [CrossRef]

13. Grossi, R.; Laura, P. Transverse vibrations of rectangular orthotropic plates with one or two free edges while the remaining are elastically restrained against rotation. Ocean Eng. 1979, 6, 527-539. [CrossRef]

14. de Irassar, P.V.; Ficcadenti, G.; Laura, P. Transverse vibrations of rectangular orthotropic plates with the edges elastically restrained against rotation and a free, straight corner cut-out. Fibre Sci. Technol. 1982, 16, 247-259. [CrossRef]

15. Grace, N.F.; Kennedy, J.B. Dynamic analysis of orthotropic plate structures. J. Eng. Mech. 1985, 111, $1027-1037$. [CrossRef] 
16. Liu, W.; Huang, C.C. Free vibration of a rectangular plate with elastically restrained and free edges. J. Sound Vib. 1987, 119, 177-182. [CrossRef]

17. Li, R.; Zhong, Y.; Tian, B.; Liu, Y. On the finite integral transform method for exact bending solutions of fully clamped orthotropic rectangular thin plates. Appl. Math. Lett. 2009, 22, 1821-1827. [CrossRef]

18. Tian, B.; Zhong, Y.; Li, R. Analytic bending solutions of rectangular cantilever thin plates. Arch. Civ. Mech. Eng. 2011, 11, 1043-1052. [CrossRef]

19. Li, R.; Tian, B.; Zhong, Y. Analytical bending solutions of free orthotropic rectangular thin plates under arbitrary loading. Meccanica 2013, 48, 2497-2510. [CrossRef]

20. An, C.; Gu, J.; Su, J. Exact solution of bending problem of clamped orthotropic rectangular thin plates. J. Braz. Soc. Mech. Sci. Eng. 2016, 38, 601-607. [CrossRef]

21. Zhang, S.; $\mathrm{Xu}, \mathrm{L}$. Bending of rectangular orthotropic thin plates with rotationally restrained edges: A finite integral transform solution. Appl. Math. Model. 2017, 46, 48-62. [CrossRef]

22. Zhang, S.; Xu, L. Analytical solutions for flexure of rectangular orthotropic plates with opposite rotationally restrained and free edges. Arch. Civ. Mech. Eng. 2018, 18, 965-972. [CrossRef]

23. Zhang, S. Vibration Serviceability of Cold-Formed Steel Floor Systems. Ph.D. Thesis, University of Waterloo, Waterloo, ON, Canada, 2017.

24. Sneddon, I. The Use of Integral Transforms; McGraw-Hill, Inc.: New York, NY, USA, 1972.

25. Khalili, M.R.; Malekzadeh, K.; Mittal, R. A new approach to static and dynamic analysis of composite plates with different boundary conditions. Compos. Struct. 2005, 69, 149-155. [CrossRef]

26. Warburton, G.B. The vibration of rectangular plates. Proc. Inst. Mech. Eng. 1954, 168, 371-384. [CrossRef]

27. Jankovic, V. The Solution of the Frequency Equation of Plates Using Digital Computers. Stavebnícky Čas. 1964, 12, 360-365. (In Czech)

28. Leissa, A.W. The free vibration of rectangular plates. J. Sound Vib. 1973, 31, 257-293. [CrossRef]

29. Jayaraman, G.; Chen, P.; Snyder, V. Free vibrations of rectangular orthotropic plates with a pair of parallel edges simply supported. Comput. Struct. 1990, 34, 203-214. [CrossRef]

30. Bassily, S.F.; Dickinson, S.M. Comment on "Free Vibrations of Generally Orthotropic Plates". J. Acoust. Soc. Am. 1972, 52, 1050-1053. [CrossRef]

(C) 2018 by the authors. Licensee MDPI, Basel, Switzerland. This article is an open access article distributed under the terms and conditions of the Creative Commons Attribution (CC BY) license (http://creativecommons.org/licenses/by/4.0/). 